\title{
ORIGEM ESCOLAR E ACESSO À EDUCAÇÃO SUPERIOR: ANÁLISE DA OCUPAÇÃO DE VAGAS DE AÇÕES AFIRMATIVAS NA UFRGS
}

\author{
CÉLIA ELIZABETE CAREGNATO ${ }^{1}$ \\ ORCID: https://orcid.org/0000-0002-9326-590X \\ HARLON ROMARIZ RABELO SANTOS ${ }^{2}$ \\ ORCID: https://orcid.org/0000-0002-5642-0448 \\ LOURENÇO BRITO FELIN ${ }^{3}$ \\ ORCID: https://orcid.org/0000-0001-5764-9693
}

\begin{abstract}
RESUMO: O artigo analisa a relação entre a heterogeneidade das escolas públicas e a ocupação das vagas da política de ações afirmativas na Universidade Federal do Rio Grande do Sul (UFRGS). A partir da literatura sobre estratificação escolar em sociologia da educação, assume-se a existência de um quasemercado escolar na rede pública, com escolas regulares e diferenciadas. Os dados explorados referem-se aos ingressos do ano de 2017. A metodologia, de cunho quantitativo, privilegiou análises descritivas, cruzamentos simples e medidas básicas de associação, caracterizando-se como um estudo exploratório. Os resultados mostram que os egressos das escolas regulares têm um acesso proporcionalmente menor às vagas reservadas na modalidade que não considera renda ou cor/raça. Esse fenômeno ocorre de forma mais intensa nos cursos mais concorridos. Considerando a heterogeneidade entre escolas públicas, a forma atual de ingresso na educação superior pública favorece egressos da escola pública diferenciada frente aos egressos da regular. Entende-se que esse fato caracteriza um limite na correção da distorção no acesso à educação superior pública federal.
\end{abstract}

Palavras-chave: ações afirmativas, estratificação educacional, escola pública, quase-mercado escolar, educação superior.

\section{SCHOOL BACKGROUND AND ACCESS TO HIGHER EDUCATION: ANALYSIS OF THE OCCUPATION OF AFFIRMATIVE ACTION QUOTAS AT UFRGS}

\begin{abstract}
The article analyzes the relation between the heterogeneity of public schools and the occupation of undergraduate student places reserved by the affirmative action policy at the Universidade Federal do Rio Grande do Sul (UFRGS). Based on the literature on educational stratification developed within Sociology of Education, this article assumes a quasi-market on public education, with regular and differentiated schools. The data explored in this article refer to students admitted in 2017. The quantitative methodology comprised descriptive analyses, crosstabulation, and basic measures of association, characterizing an exploratory study. The results show that students from regular public

\footnotetext{
${ }^{1}$ Universidade Federal do Rio Grande do Sul (UFRGS). Porto Alegre, RS, Brasil. < celia.caregnato@gmail.com>

${ }^{2}$ Universidade Federal do Rio Grande do Sul (UFRGS). Porto Alegre, RS, Brasil. < harlon.romariz@gmail.com>

${ }^{3}$ Universidade Federal do Rio Grande do Sul (UFRGS) . Porto Alegre, RS, Brasil. <lofelin@gmail.com> 
schools have a more limited access to reserved places in the quotas which do not consider income or race. This phenomenon is more intense in the most competitive programs. Considering the heterogeneity among public schools, the current procedures favor the admission in public higher education of graduates from differentiated public schools rather than students who attended regular public schools. This fact is understood as a limit in the remediation of distortions in the access to federal public higher education.

Keywords: affirmative actions, educational stratification, public school, school quasi-market, higher education.

\section{ORIGEN ESCOLAR Y ACCESO A LA EDUCACIÓN SUPERIOR: ANÁLISIS DE LA OCUPACIÓN DE VACANTES DE ACCIÓN AFIRMATIVA EN UFRGS}

RESUMEN: El artículo analiza la relación entre la heterogeneidad de las escuelas públicas y la ocupación de las vacantes de acción afirmativa en la Universidad Federal de Rio Grande do Sul (UFRGS). A partir de la teoría sobre la estratificación escolar desarrollada en la sociología de la educación, asumimos la existencia de un casi-mercado escolar en el sector público de educación, con escuelas regulares y diferenciadas. Los datos explorados se refieren a los entrantes de 2017. La metodología, de naturaleza cuantitativa, empleó el análisis descriptivo, los cruces simples de variables y las medidas básicas de asociación, caracterizándose como un estudio exploratorio. Los resultados muestran que los estudiantes de las escuelas regulares tienen un acceso proporcionalmente menor a los lugares reservados en la modalidad que no considera renta o color/raza. Este fenómeno ocurre más intensamente en los cursos más competitivos. Considerando la heterogeneidad entre las escuelas públicas, la forma actual de acceso a la educación superior pública favorece a los graduados de las escuelas públicas diferenciadas en comparación a las regulares. Se entiende que este hecho caracteriza un límite para corregir la distorsión en el acceso a la educación superior pública federal.

Palabras clave: acciones afirmativas, estratificación educacional, escuela pública, casi-mercado escolar, educación superior.

\section{INTRODUÇÃO}

A escolarização de nível médio não é homogênea no sistema educacional brasileiro. Para além da distinção entre mantenedoras - públicas ou privadas - das escolas, há diversidade expressiva no interior de cada um desses segmentos (NOGUEIRA, 1998; COSTA, 2008). Há mercado de vagas, especialmente entre escolas de alta competitividade e de altos custos financeiros, vistas com maior potencialidade de acesso ao ensino superior. A relação entre condições sociais prévias (origem social) e trajetória escolar potencializa o acesso à educação superior, restrita a alguns segmentos sociais.

A política de cotas em vagas nas instituições federais de educação superior brasileiras, sistematizada na Lei 12.711/2012, visa garantir o acesso de públicos historicamente sub-representados a esse nível de ensino. Todas as modalidades de reserva de vagas são destinadas a estudantes egressos de escolas públicas, porém uma delas não contempla a heterogeneidade de renda e/ou racial presente na rede pública de ensino médio brasileira. Dessa forma, é valido colocar atenção sobre o modo como as vagas reservadas pela política de ações afirmativas se distribuem entre egressos de diferentes categorias de escolas públicas. O artigo apresenta dados da reserva de vagas na UFRGS em 2017, demonstrando haver diferença na ocupação das modalidades entre estudantes oriundos de escolas públicas regulares e de escolas públicas diferenciadas, sobretudo quando associada aos condicionantes de renda e raça. 


\section{CONTEXTOS DE ACESSO AO ENSINO SUPERIOR E POLÍTICAS DE COTAS}

A expansão da escolarização média e superior no Brasil ocorre, especialmente, no fim dos anos 1990 e na primeira década dos anos 2000, evidenciando avanços e limites diante dos objetivos nacionais para esses níveis de ensino, conforme as metas do Plano Nacional de Educação (PNE, 2014). Embora o contingente de estudantes nesses níveis educacionais se tenha ampliado, há limites no processo de ampliação do acesso, como também na persistência de desigualdades quanto ao ingresso.

De acordo com Arretche (2015), no intervalo de cinquenta anos entre as décadas de 1960 e 2010, houve um padrão misto das desigualdades: as que se referem às oportunidades educacionais foram reduzidas nos níveis educacionais básicos; no ensino médio, ocorreu persistência de graves desigualdades; e houve deslocamento de novos tipos de desigualdades para o nível superior. Arretche (2015) mostra que a situação social dos indivíduos é fator básico para suas chances de progressão e de transição para novas fases na vida escolar. A expansão do acesso nos níveis de ensino básicos deslocou os efeitos da origem social para etapas de ensino mais avançadas. A partir dos anos 1990, os obstáculos à progressão educacional se localizam mais fortemente na conclusão do ensino médio e no ingresso na educação superior (ARRETCHE, 2015, p. 107).

Nos anos 2000, paralelamente à ampliação de vagas no ensino médio e na educação superior, ocorreram debates e decisões em torno da ampliação ao direito à educação e à necessidade de compensação frente a exclusões históricas de certos segmentos sociais. Como resultado do debate nacional, foram produzidos documentos oficiais que traduziam mudanças, caso do Programa Universidade para Todos (Prouni), voltado para oferecimento de bolsas de estudos em instituições privadas de educação superior e aprovado pela Lei 11.096/2005. De outra parte, houve a aprovação da Lei 12.711/2012, depois de disputas políticas e de uma série de iniciativas de instituições públicas de educação superior que implantavam sistemas de reservas de vagas. Isso significou um esforço, não visto anteriormente, para responder a desigualdades no acesso à educação superior com vagas reservadas pelas universidades, principalmente para segmentos autoidentificados em termos étnico-raciais.

Apesar de avanços, as universidades públicas permaneciam seletivas, com estudantes oriundos de classe média, de cor branca e majoritariamente egressos de escolas privadas (OLIVEN, 2009; CAREGNATO, OLIVEN, 2017). Entretanto, a atuação dos movimentos sociais e as tomadas de decisões institucionais e estatais contribuíram para a elaboração de medidas que propiciaram certa democratização no acesso ao ensino superior (MOEHLECKHE, 2002; ANHAIA, 2019). Nesse contexto, discutia-se a pertinência de cotas sociais e raciais na relação com objetivos de reparação, justiça distributiva e de afirmação da diversidade, havendo disputa entre perspectivas adotadas por diferentes grupos sociais (FERES JÚNIOR, 2005).

A política de cotas para ingresso nas instituições de ensino superior federais pode ser entendida como uma política compensatória que visa incidir sobre a diminuição de desigualdade (MOEHLECKHE, 2002). Nesse sentido, a lei de 2012 reservou 50\% das vagas para egressos de escolas públicas, sendo definindo ainda que: 1) metade delas são destinadas a estudantes oriundos de famílias com renda per capita inferior a 1,5 salários mínimos mensais; e 2) percentual de vagas proporcional à distribuição populacional étnico racial da unidade da federação da Ifes - com base em dados de autodeclaração de cor no Censo Demográfico do Instituto Brasileiro de Geografia e Estatística (IBGE) - destinado para candidatos pretos, pardos ou indígenas (Lei 12.711/2012). A Lei 13.409 de 28 de dezembro de 2016 incluiu a reserva de vagas para pessoas com deficiência, o que passou a ser implementado a partir dos processos seletivos de 2018 na UFRGS e, portanto, não será objeto deste estudo. A lei evidencia o entendimento de que estudantes egressos de escolas públicas formam um segmento legítimo para ingressar na universidade com base em concorrência entre si. Dessa forma, o segmento de escolas públicas, independente dos seus tipos - integral, profissionalizante, entre outras e/ou rede mantenedora - ensino federal, estadual ou municipal -, foi visto como único, sem consideração a distinções internas. 
Entretanto, a homogeneidade interna ao sistema não é real. As trajetórias e os desempenhos escolares de estudantes oriundos de escolas caracterizadas por algum tipo de disputa seletiva no ingresso para o ensino médio evidenciam variações nas capacidades competitivas oferecidas pelas escolas públicas para ingresso na educação superior. Além de selecionar estudantes, as escolas seletivas/diferenciadas também são objeto de interesse e mobilização de famílias que investem mais em projetos de escolarização para seus filhos. Nogueira et al. (2017), em análise sobre o ingresso de estudantes pelo Sistema de Seleção Unificada (Sisu, criado em 2010) na Universidade Federal de Minas Gerais, mostram que o perfil geral dos estudantes não foi alterado significativamente. Destaca, por outro lado, que ocorreram mudanças importantes no perfil dos ingressantes com base em duas categorias: (i) a rede de ensino médio da qual o estudante é egresso - municipal, estadual e federal; (ii) os cursos e o turno para os quais se destina o ingressante na universidade. Assim, os estudantes egressos de escolas federais ingressaram em percentual relativamente maior entre os anos de 2010 e 2015, se comparados aos egressos de escolas estaduais e municipais. Em contrapartida, o aumento proporcional de egressos de escolas públicas federais ocorreu também em cursos de maior competitividade no ingresso, como é o caso de enfermagem e medicina, e no turno diurno em relação ao noturno (NOGUEIRA et al., 2017).

Em convergência com essa análise, Salata (2018) mostra que houve redução da desigualdade no sistema de educação superior em termos gerais nas últimas duas décadas e que as políticas públicas que objetivavam esse arrefecimento se constituíram em ferramentas indispensáveis para haver não somente ampliação, mas também democratização no acesso. Por outro lado, o mesmo autor apresenta evidências de que, quando são consideradas variáveis específicas, certos desníveis se mantêm ou sofrem menor diminuição. Variáveis como o tipo de instituição e o tipo de curso evidenciam redução proporcionalmente menor da desigualdade frente à variável acesso à educação superior por novas camadas sociais de estudantes, tomada em sentido amplo.

As políticas de ações afirmativas constituem importante instrumento de combate às desigualdades na educação brasileira. Nesse sentido, um olhar atento à ocupação das vagas reservadas às ações afirmativas na universidade representa uma estratégia de ampliação sobre a percepção da reprodução de tais desigualdades e, portanto, objeto da investigação que favorece a explicitação da estratificação horizontal no âmbito da heterogeneidade da escola pública.

\section{AS AÇÕES AFIRMATIVAS NA EDUCAÇÃO SUPERIOR}

As experiências de ações afirmativas apresentam significativas variações conforme seu desenvolvimento em termos de países (EUA, países da Europa Ocidental, Índia, Malásia, Austrália, Canadá, Nigéria, África do Sul, Argentina, Cuba, dentre outros), formas (ações voluntárias, de caráter obrigatório, ou uma estratégia mista; programas governamentais ou privados; leis e orientações a partir de decisões jurídicas ou agências de fomento e regulação), públicos a que se destinam (minorias étnicas, raciais, gênero, entre outros), áreas de abrangência (mercado de trabalho; sistema educacional; e representação política), bem como diversos desenhos de suas práticas através de percentual de vagas proporcional ou não; e, por fim, em termos de taxas e metas (MOEHLECKE, 2002).

Tão complexos quanto as modalidades (formas) de ações afirmativas experienciadas nesses contextos são os conteúdos que justificam e envolvem o debate conceitual sobre a terminologia. Buscando sintetizar as diferentes contribuições, Moehlecke (2002, p. 203) define ação afirmativa como

[...] uma ação reparatória/compensatória e/ou preventiva, que busca corrigir uma situação de discriminação e desigualdade infringida a certos grupos no passado, presente ou futuro, através da valorização social, econômica, política e/ou cultural desses grupos, durante um período limitado. A ênfase em um ou mais desses aspectos dependerá do grupo visado e do contexto histórico e social.

De acordo com Feres Júnior (2008), três argumentos são usados para justificar a ação afirmativa nos vários países em que essa modalidade de política pública é empregada: reparação, justiça social e diversidade. No Brasil, o autor refere que os argumentos da reparação e da diversidade têm mais 
destaque, enquanto a questão da justiça social em geral não é considerada. Defende, porém, que "a justiça social deveria ter papel justificativo preponderante, secundada pela reparação, enquanto a diversidade não deveria ter tanta relevância" (FERES JÚNIOR, 2005, p. 55).

Todas essas compreensões sobre as ações afirmativas incorrem em posicionamentos políticos que as sustentam ou se contrapõem a elas de acordo com cada cenário. Neste estudo, interessanos situar o debate sobre as ações afirmativas no âmbito do acesso à educação superior, mais especificamente tendo como objeto de análise aspectos da política de cotas aplicada no contexto na Universidade Federal do Rio Grande do Sul.

A discussão sobre a política de reserva de vagas teve amplo debate no Congresso Nacional, com iniciativas que remontam ao início da década de 1990, com a proposta de Emenda Constitucional do então deputado federal Florestan Fernandes (PT/SP). A etapa que corresponde à tramitação da Lei de Reserva de Vagas levou treze anos, iniciando pelo Projeto de Lei (PL) 73 de 1999, perpassando outras 16 proposições parlamentares (incorporando predominantemente as sugestões do PL no 3.627 de 2004) e percorrendo cinco comissões do Congresso Nacional. A análise dos discursos dos agentes políticos envolvidos na tramitação legislativa, realizada por Anhaia (2019), demonstra que as escolas públicas são predominantemente representadas como de infraestrutura deficitária, ofertando formação de baixa qualidade e recebendo pouco investimento, enquanto as escolas particulares possuem melhores recursos e ofertam ensino de melhor qualidade. Assim, a leitura política que sustentou a aprovação das cotas nas instituições federais de educação superior mobilizou como argumentos fundamentais a baixa qualidade do ensino básico público e aspectos socioeconômicos relacionados à desigualdade do acesso à educação superior, como o racismo, a desvalorização da educação, a defesa do mérito individual e a discriminação etária (ANHAIA, 2019).

Portanto, a política de ações afirmativas, aprovada pela Lei 12.711/2012, foi precedida por intensos debates políticos e por políticas institucionais que se anteciparam, implementando regras específicas com o objetivo de induzir o ingresso de públicos estudantis até então ausentes ou com presença precária nas universidades. As universidades públicas, especialmente desde o ano de 2002, trabalharam para a redução da desigualdade no acesso a vagas, considerando variáveis como baixa renda, raça e escolarização pregressa.

O problema da desigualdade no acesso a vagas da educação superior no País está sendo enfrentado com políticas estatais, institucionais e com o trabalho de indivíduos e grupos sociais que se organizam para propiciar condições de estudos. Tudo isso é crucial para proporcionar oportunidades aos jovens estudantes, mas também não impede que certas desigualdades escolares pregressas continuem sendo marcantes nas suas trajetórias de formação acadêmica.

\section{ESTRATIFICAÇÃO EDUCACIONAL E HETEROGENEIDADE DO SISTEMA BÁSICO DE ENSINO}

O século XX foi marcado por um aumento significativo na oferta escolar, sobretudo entre os países ocidentais. A defesa da universalização da educação em todos os seus níveis era acompanhada da crença de que a educação podia promover mobilidade social e tornar as sociedades mais igualitárias (MASSON, 2016). Em meados desse século, vários estudos mostraram que a educação por si só não promove mobilidade social ou garante igualdade de oportunidades. Pelo contrário, a escola pode acabar por reproduzir desigualdades sociais previamente existentes (HAECHT, 2008). Destacam-se nessa linha os trabalhos de Bourdieu, Passeron (2012) e Boudon $(1979,1981)$ na França, e de Coleman (1966) nos Estados Unidos. Entre as décadas de 1970 e 1990, os estudos em estratificação educacional e social investiram na análise das transições educacionais e no acúmulo de anos de estudo como variável importante na compreensão da posição social dos indivíduos e nas suas capacidades de realização educacional e social. A análise de Samuel Lucas (2001; 2009), no âmbito da teoria da desigualdade efetivamente mantida, apresenta a necessidade de refinar o estudo dos processos de escolarização, entendendo-os como não lineares e construídos por legitimações em espaços de distinções importantes. Dessa forma, os efeitos da origem social podem ser vistos não apenas nos anos iniciais da escola, mas ao 
longo da trajetória escolar da formação dos indivíduos. Eles manifestam-se na relação com o progresso no sistema de ensino, em termos de anos de estudos concluídos, mas impactam também a posição, a trajetória e o tipo de educação alcançada.

Com os processos de universalização do ensino ou pelo menos de massificação, os acirramentos e disputas pelas melhores posições, currículos e/ou carreiras de maiores distinções aumentam. Torna-se relevante analisar não apenas a progressão escolar e o acúmulo de anos de estudos, como fazem os estudos tradicionais em estratificação educacional. As análises em estratificação horizontal centralizam-se em aspectos mais detalhados, em caminhos e processos específicos que revelam estratégias de agentes para uma progressão educacional qualitativamente orientada. É nesse quadro histórico e teórico que se situam as análises que exploram os diversos caminhos e posições possíveis dentro de um sistema educacional, ou num dos seus níveis. Essas análises valorizam e focam a heterogeneidade dos sistemas de ensino e pensam as ações dos agentes educacionais também como competições pelas melhores oportunidades do sistema, nos quais as condições socioeconômicas importam.

É possível, desde que um determinado nível de escolaridade não seja universal (por exemplo, a conclusão do ensino médio durante a primeira metade do século XX nos Estados Unidos), que os privilegiados socioeconomicamente usem suas vantagens para garantir esse nível de escolaridade. Uma vez que este nível de escolaridade se torne quase universal, no entanto, os socioeconomicamente privilegiados procuram quaisquer diferenças qualitativas que existem nesse nível e usam suas vantagens não para assegurar uma educação quantitativamente similar, mas qualitativamente melhor (LUCAS, 2001, p. 1652, tradução livre).

Para analisar a busca de vantagens na heterogeneidade do sistema escolar resultante desse processo de disputa social no contexto brasileiro, autores como Márcio da Costa e Mariane Koslinski desenvolveram duas categorias de análises articuladas. A primeira é a noção de escola pública diferenciada utilizada por Costa (2008) para se referir àquelas escolas que: (I) recebem uma demanda maior que sua capacidade de oferecer vagas e, por isso, incluem algum tipo de processo seletivo para o ingresso, como entrevistas, provas formais ou sorteios; e (II) ampliam as chances competitivas de seus egressos em relação a outras escolas devido a diferenciações curriculares e/ou de infraestrutura. Essa ideia de escolas diferenciadas efetiva-se como uma categoria contextual e relativa ante a compreensão de que existe um quase-mercado escolar na rede pública de ensino (COSTA; CAMARGO, 2010). Como apresentam Costa e Koslinski (2011; 2012) e Rosistolato (2015), apesar da parcial liberdade de escolha escolar por parte das famílias, há uma clara competição por escolas públicas diferenciadas, que ocorre por diversos motivos e de várias maneiras, conforme os atores familiares buscam as oportunidades escolares que julgam ser as melhores para seus filhos.

O conceito de mercado escolar é facilmente aplicável à realidade do ensino privado. Contextualizar esse conceito na realidade da escola pública brasileira é, entretanto, desafiador (COSTA; KOSLINSKI, 2011). A ideia de quase-mercado comunica-se à prática da escolha escolar em situação de parcial liberdade de escolha. No caso das escolas públicas, a liberdade de escolha da escola pelas famílias é limitada por questões legais e burocráticas. Essa situação é presente em vários países e pode configurarse seja como um quase-mercado escolar regulamentado, seja como um quase-mercado escolar oculto. Para que o conceito seja devidamente apropriado no caso brasileiro, são necessárias algumas considerações iniciais. Ao tratar da rede pública, ele envolve

[...] a disputa por escolas públicas que não podem ser propriamente caracterizadas como de elite ou de excelência, mas que têm a reputação de escolas de boa qualidade. [...] Pode-se afirmar que existe um expressivo quase-mercado educacional no Brasil, tal como caracterizado na discussão originária do pensamento econômico e das reformas educacionais desencadeadas nas últimas décadas do século XX. Esse quase-mercado apresenta, porém, características originais, uma vez que seus mecanismos são pouco visíveis ou mesmo deliberadamente ocultados. [...] Entre essas escolas ou entre as escolas privadas, é fácil falar de mercado e de escolha escolar (school choice). Nosso foco, contudo, se volta a um fenômeno menos visível, mas de mobilização igualmente acirrada: a disputa por escolas que não frequentam os topos dos rankings, não costumam 
aparecer em matérias jornalísticas ou não obtêm destaque fora do âmbito restrito do público a que atendem (COSTA; KOSLINSKI, 2011, p. 246; 248; 250, grifo do autor).

A operação analítica consequente à identificação do quase-mercado envolve caracterizar o reconhecimento do público atendido ("clientes") em torno da qualidade de algumas escolas públicas em relação a outras escolas públicas de menor reputação. Esse reconhecimento dá-se de forma não aparente, mas revela uma capacidade e vontade de seleção da "melhor" escola disponível na rede pública. O conceito de quase-mercado escolar (COSTA; CAMARGO, 2010) pode ajudar a considerar essa prática.

Costa e Koslinski (2012) apontam para a existência de dispositivos competitivos, agenciados tanto pelas famílias quanto pela burocracia escolar. Essa dinâmica, intensificada pela ausência de regulamentação, vai criando as condições para a legitimação de hierarquias escolares. O conceito de quase-mercado é eficiente para se pensar essa dinâmica, por vezes formal e clara, por vezes informal e oculta, de interesse por escolas mais procuradas, escolhidas para além das conveniências práticas. As condições socioeconômicas das famílias que tomam parte nessa disputa e seu capital social são variáveis importantes na compreensão dessa dinâmica de parcial liberdade, de busca e escolha limitada, que se relaciona com expectativas e desejos das escolas ao tentarem se posicionar nesse quase-mercado. As regras do sistema, as informações disponíveis, a forma como se organizam as matrículas, os interesses dos gestores escolares e diversos outros elementos contextuais, sociais e institucionais são parte dessa estrutura e influenciam essa dinâmica de escolha e permanência escolar no âmbito da escola pública. Todos esses dispositivos repercutem na competição pelo acesso à educação superior.

A estratificação educacional e a heterogeneidade de experiências escolares jogam papel importante no acesso e na permanência à universidade. Essas desigualdades podem ser verificadas na definição da vaga de acesso, do curso, do turno de estudo, assim como na desenvoltura maior ou menor para responder aos desafios da vida acadêmica.

\section{METODOLOGIA}

Para analisar a diferença na ocupação das vagas de cotistas, optou-se por análises descritivas, cruzamentos simples e medidas básicas de associação, caracterizando um estudo exploratório. Os dados acessados referem-se a 2.538 cotistas, obtidos junto à Pró-Reitoria de Graduação (Prograd) da UFRGS em maio de 2018, em formato de microdados. Após trabalho de organização de dados ${ }^{4}$, chegou-se a um banco de dados final com 21 variáveis, refletindo as informações de matrícula e ingresso dos cotistas UFRGS ingressantes em 2017.

Para atender ao objetivo, foi necessário coletar manualmente os dados da origem escolar por meio do sistema de acompanhamento de homologação das vagas da Prograd ${ }^{5}$. Optou-se por analisar os dados de 2017 uma vez que: (i) na ocasião da coleta dos dados, as vagas do ano de 2018 ainda não estavam completamente ocupadas; (ii) 2017 foi o último ano de ingresso com os critérios estabelecidos originalmente na Lei 12.711 de 2012, sem inclusão de cotas para pessoas com deficiência; (iii) 2017 foi o ano em que se asseguraram os percentuais de 70\% das vagas para o CV e 30\% para o Sisu.

Por ser o tipo de curso uma variável importante para a análise, optou-se por ranquear os cursos da UFRGS disponíveis no CV 2017 pela nota de corte $^{6}$ do acesso universal e pela densidade ${ }^{7}$ desse concurso, possibilitando reconhecer os cursos com alta procura e difícil acesso. Em diálogo com o campo de estudos sobre heterogeneidade escolar, em sociologia da educação, foram classificadas como escolas públicas diferenciadas aquelas escolas que requerem ingresso diferenciado, que possuem características que agregam maior capacidade competitiva aos seus egressos e que são buscadas por um

\footnotetext{
${ }^{4}$ Os autores agradecem as atividades desenvolvidas pelas estudantes de graduação na condição de bolsistas de iniciação científica com bolsas FAPERGS e CNPq, durante o período 2018/2019.

5 Tais dados foram construídos a partir de projeto de pesquisa aprovado no Comitê de Ética em Pesquisa da UFRGS.

${ }^{6}$ Nota de corte equivale à nota obtida pelo estudante que se classificou e obteve vaga com o menor escore para ingresso no processo seletivo do seu curso.

${ }^{7}$ Densidade representa o número resultante da divisão do total de candidatos inscritos pelo número de vagas disponíveis para ingresso em um determinado curso, descrevendo a relação candidato/vaga. 
grupo social distinto da média das escolas públicas. Assim, duas condições são necessárias: (i) ter algum tipo de processo diferenciado de acesso, que implica algum nível de seletividade no ingresso, seja direto ou indireto; (ii) ter algum fator agregador aos estudantes e egressos (tempo integral, formação técnica e/ou rendimento escolar acima da média).

A decisão por apresentar apenas estatísticas descritivas e cruzamentos simples ocorreu pelo fato de não ser eficiente utilizar testes inferenciais quando os dados disponíveis não são amostrais e não aleatórios (MAGALHÃES; LIMA, 2013). São dados administrativos de acesso limitado e que requereram esforço singular para obtenção e organização. Além disso, a pouca quantidade de variáveis teoricamente significantes inviabiliza uma análise causal multivariada, o que faz com que os modelos tenham baixo poder explicativo.

Dessa forma, faz-se necessário, para aprofundamentos posteriores, que tais dados tenham continuidade de coleta, ao longo dos anos, e que agreguem outras variáveis que permitam uma análise quantitativa mais elaborada e significativa. Os resultados são apresentados a seguir, expondo: (i) a relação entre origem escolar e distribuição das vagas ocupadas nas diferentes modalidades de cotas (L1, L2, L3/L5 e L4/L6) em todos os cursos da Universidade; (ii) a relação entre origem escolar e distribuição de vagas nos dez cursos de maior concorrência e dificuldade de acesso; (iii) a relação entre origem escolar e distribuição de vagas no curso de maior concorrência e maior dificuldade de acesso - medicina; (iv) a relação entre origem escolar e distribuição de vagas nos dez cursos de menor concorrência e maior facilidade de acesso.

\section{UMA ANÁLISE SOBRE A OCUPAÇÃO DAS VAGAS DA POLÍTICA DE COTAS NA UFRGS}

Na UFRGS, o processo de implantação de reserva de vagas em cursos de graduação foi extensamente analisado a partir dos estudos de Bello (2011), Souza (2017), Prolo (2011), Grisa (2010; 2015), José (2017), Lopez (2009) e Nogueira (2015). Neles, podemos perceber a discussão ampla envolvendo Grupos de Trabalho desde 2005 (compostos por professores, estudantes, técnicos negros da universidade que tinham vínculo de militância com o movimento negro e militantes de movimentos e organizações sociais antirracistas vinculados ou não à universidade) até a aprovação da Decisão do Conselho Universitário (Consun) em 2008 e posterior adequação à política nacional de cotas (Lei $12.711 / 2012)$ através da Decisão $n^{\circ} 268 / 2012$, ainda vigente com as modificações realizadas pelas Decisões no 429/2012, 406/2013, 245/2014, 312/2016 e 212/2017.

Uma busca realizada sobre dissertações e teses produzidas nos programas de pós-graduação da UFRGS sobre cotas na universidade demonstra que os estudos, em sua maioria, têm abordado a discussão a partir do recorte racial, com metodologias qualitativas, destacando a implantação da política institucional e o acompanhamento das trajetórias e estratégias de permanência dos alunos cotistas ${ }^{9}$. Nesse sentido, observa-se que a relação entre origem escolar e acesso à educação superior através das modalidades de cotas não tem sido objeto de análise nessas produções.

Com o objetivo de incidir sobre essa lacuna, este estudo pretende refletir sobre a relação entre origem escolar e ocupação das vagas, identificando a prevalência das escolas regulares e diferenciadas na distribuição desta ocupação entre as diferentes modalidades de cotas e cursos dos processos seletivos Vestibular/Sisu 2017.

No sistema de seleção da UFRGS, 70\% das vagas anuais da universidade são atribuídas por meio do Concurso Vestibular (CV). As vagas relativas a esse processo seletivo são ocupadas

\footnotetext{
8 Trata-se de escolas federais ligadas ao Ministérios da Educação, ao Ministério da Defesa, e de escolas diferenciadas de redes estaduais. Estudantes oriundos de escolas da Região Sul $(93,1 \%)$, da Região Sudeste (5,3\%), Região Norte $(0,7 \%)$, Região Nordeste $(0,5 \%)$ e Região Centro-Oeste $(0,4 \%)$.

${ }^{9}$ Foram identificadas 41 produções (36 dissertações e 15 teses) relativas ao tema das Ações Afirmativas realizadas nos diferentes programas de pós-graduação da UFRGS. A temática racial (PPI) prevaleceu em 23 produções, compartilhando preocupações com Assistência Estudantil, permanência, processo de formulação e implementação da política de cotas, renda, curso pré-vestibular popular, comparativo com Prouni, origem geográfica dos estudantes, Pessoas com Deficiência, estratégias institucionais de comunicação e discussão teórico conceitual. Com relação à metodologia, prevalece a abordagem qualitativa (33), seguida pela híbrida quanti-quali (8).
} 
majoritariamente por candidatos residentes no estado do Rio Grande do Sul (RS). No ano de 2017, $97,73 \%$ (3.839) dos estudantes que ingressaram por esse processo seletivo residiam no RS. Observa-se, ainda, que há predominância da região metropolitana entre os inscritos, sobretudo Porto Alegre, com 50,38\% (15.514). Os demais 30\% das vagas são ofertados pelo Sistema de Seleção Unificado (Sisu).

Ambas as formas de seleção, CV e Sisu, previam, em 2017, a reserva de 50\% do total das vagas para egressos de escolas públicas, igualmente distribuídas, ou seja, 12,5\% do total de vagas para cada uma das quatro modalidades de cotas, assim caracterizadas:

L1: Candidato egresso do sistema público de ensino médio com renda familiar bruta mensal igual ou inferior a 1,5 salário-mínimo nacional per capita.

L2: Candidato egresso do sistema público de ensino médio com renda familiar bruta mensal igual ou inferior a 1,5 salário-mínimo nacional per capita autodeclarado preto, pardo ou indígena.

L3/L5: Candidato egresso do sistema público de ensino médio, independente da renda familiar. L4/L6: Candidato egresso do sistema público de ensino médio, independente da renda familiar, autodeclarado preto, pardo ou indígena.

As demais vagas, não reservadas, que correspondem a $50 \%$ da totalidade, não estão submetidas a qualquer outro tipo de reserva, sendo consideradas, portanto, de acesso universal. De outra parte, essas vagas podem ser ocupadas por candidatos inscritos nas modalidades de reserva à medida que obtenham o desempenho suficiente para se classificarem no ordenamento geral dos candidatos.

As vagas disponibilizadas pelo CV no ano de 2017 totalizaram 4.017, tendo sido ocupadas 3.928. O número total de inscritos nesse processo seletivo foi de 33.459. Só no curso de medicina, houve 7.277 inscritos, gerando uma densidade de 74,26 candidatos por vaga. A maioria dos candidatos inscritos declarou cor branca (27.264 ou 81,48\%). No entanto, o número de aprovados desse segmento foi de $73,35 \%$. Esse dado indica que a reserva de vagas étnico-raciais atende relativamente o objetivo de acesso de pessoas pretas e pardas através do CV 2017 (925 ou 23,55\%) (UFRGS/COPERSE, 2017, p. 22). O dado mostra que há ingresso de pessoas pretas, pardas e indígenas proporcional aos percentuais estabelecidos pela política de cotas. Interessa entender a origem escolar dos ingressantes.

Quanto à origem escolar, os dados da Tabela 1 permitem observar que há um aumento percentual proporcional entre inscritos e aprovados apenas para o segmento de estudantes que cursou ensino médio integralmente em escola pública, o perfil correspondente ao critério básico para todas as modalidades de cotas. Consequentemente, há redução na proporção entre inscritos e aprovados para todos os demais segmentos.

Tabela 1 - Origem escolar entre inscritos e aprovados no CV/2017 - UFRGS.

\begin{tabular}{|c|c|c|c|c|}
\hline Ensino Médio & Inscritos & $\%$ & Aprovados & $\%$ \\
\hline Escola pública - integralmente & 16.290 & $48,69 \%$ & 2.373 & $60,41 \%$ \\
\hline Escola pública - maior parte & 1.457 & $4,35 \%$ & 76 & $1,93 \%$ \\
\hline Escola particular - integralmente & 10.855 & $32,44 \%$ & 1.149 & $29,25 \%$ \\
\hline Escola particular - integralmente - com bolsa & 955 & $2,85 \%$ & 70 & $1,78 \%$ \\
\hline Escola particular - integralmente - bolsa parcial & 1.404 & $4,20 \%$ & 115 & $2,93 \%$ \\
\hline Escola particular - maior parte & 1.645 & $4,92 \%$ & 91 & $2,32 \%$ \\
\hline Escola particular - maior parte - bolsa integral & 268 & $0,80 \%$ & 18 & $0,46 \%$ \\
\hline Escola particular - maior parte - bolsa parcial & 585 & $1,75 \%$ & 36 & $0,92 \%$ \\
\hline Total & 33.459 & & 3.928 & \\
\hline
\end{tabular}

Fonte: UFRGS/COPERSE, 2017.

Todas as modalidades de acesso apresentam maior número de inscritos e habilitados do que vagas. As modalidades que contam com menor número de inscritos tanto em números absolutos como proporcionalmente são aquelas que reservam vagas para estudantes autodeclarados pretos, pardos e indígenas, que correspondem às modalidades L2 e L4 e totalizam 3.356 inscritos, ou seja, 10,03\% dos candidatos. No entanto, observa-se que nessas modalidades há um número inferior de classificados em 
relação às vagas ofertadas - 392 classificados para 540 vagas na L2; e 431 classificados para 522 vagas na L4. Essa situação ocorre porque os candidatos habilitados se concentram nos cursos de maior concorrência, enquanto o número de habilitados nos cursos de menor concorrência é inferior ao número de vagas ofertadas. Assim, as vagas reservadas que não são preenchidas por seu público-alvo são abertas para outras modalidades de cotas.

Tabela 2 - Modalidades de inscrição, habilitação e classificação dos candidatos no CV/2017, UFRGS.

\begin{tabular}{|c|c|c|c|c|}
\hline Modalidade de Inscrição & Vagas & Inscritos & Habilitados & Classificados \\
\hline Universal & 1.989 & 17.620 & 5.783 & 1.533 \\
\hline Modalidade L1 & 500 & 4.996 & 1.877 & 643 \\
\hline Modalidade L2 & 540 & 1.656 & 660 & 392 \\
\hline Modalidade L3 & 466 & 7.487 & 3.003 & 929 \\
\hline Modalidade L4 & 522 & 1.700 & 812 & 431 \\
\hline Total & 4.017 & 33.459 & 12.135 & 3.928 \\
\hline
\end{tabular}

Fonte: UFRGS/COPERSE, 2017.

Entre os habilitados para a modalidade de cotas L3, 370 deles ocupam vagas da modalidade Universal, tendo em vista o desempenho suficiente para classificação na modalidade de acesso de ampla concorrência. Dessa forma, do total de vagas destinadas à ampla concorrência, 18,6\% são preenchidas por candidatos inscritos na modalidade L3. Entre os candidatos inscritos nas outras modalidades de reserva de vagas (L1, L2 e L4), 86 ingressam nas vagas na ampla concorrência (4,32\%). O perfil da modalidade de cota L3 (egressos de escolas públicas sem condicionante de renda e/ou étnico-racial) ocupa um número significativo das vagas de ampla concorrência, ou seja, no ano de 2017, além das 466 vagas reservadas e ocupadas, 370 candidatos deste perfil ocuparam vagas na ampla concorrência. Dito de outra forma, do total de candidatos inscritos pela modalidade L3 que efetivamente ingressaram na universidade, 44,25\% foram lotados em vagas da ampla concorrência. Esse fato indica a necessidade de estudar se esse perfil corresponde a um grupo socioeducacional em desvantagem quanto ao acesso à educação superior. Os dados que serão apresentados no item resultados detalham a relação entre a origem escolar e a desvantagem para o acesso ao ensino superior.

Considerando a heterogeneidade da rede pública de nível médio no Brasil, o objetivo estabelecido para esse trabalho foi verificar se existe diferença na ocupação da vaga entre cotistas oriundos de diferentes tipos de escolas públicas na UFRGS e descrever como ocorre essa ocupação entre os distintos cursos. As hipóteses eram de que havia diferença na ocupação das vagas reservadas pela política de cotas entre cotistas de diferentes tipos de escolas públicas; essa diferença é mais intensa nos cursos de maior concorrência ${ }^{10}$.

\section{Descrição e análise dos resultados}

O total de cotistas com ocupação da vaga em 2017 que compõem o banco de dados analisado foi de 2.538. Com relação ao tipo de ingresso, $28,2 \%$ ocuparam vaga por meio do Sisu, e $71,8 \%$, pelo CV UFRGS. Embora em 2017 a distribuição das vagas reservadas às ações afirmativas na UFRGS fosse similar entre as quatro modalidades de cotas (25\% para cada), a ocupação efetiva dessas vagas variou, conforme Tabela 3.

Tabela 3 - Distribuição na ocupação das modalidades de cota, UFRGS, 2017.

\footnotetext{
${ }^{10}$ Os cursos de maior ou menor concorrência foram classificados com base na relação entre candidatos inscritos e vagas ofertadas, e no escore mínimo para classificação no CV do 2017. Dessa forma, o cálculo objetivo foi um produto entre nota de corte (dificuldade de acesso) e densidade (concorrência). 


\begin{tabular}{|c|c|c|}
\hline Modalidade & Frequência & $\%$ \\
\hline L1 & 653 & 25.7 \\
\hline L2 & 500 & 19.7 \\
\hline L3 & 788 & 31.0 \\
\hline L4 & 597 & 23.5 \\
\hline Total & 2538 & 100 \\
\hline
\end{tabular}

Fonte: Elaborado a partir de banco de dados da PROGRAD/UFRGS.

A partir da categorização adotada, e considerando a última escola de ensino médio frequentada pelos candidatos, entre os cotistas que ocuparam vagas na UFRGS em 2017, 26\% eram oriundos de escolas diferenciadas e $74 \%$ de escolas regulares, em percentuais válidos (ver Figura 1). Foram desconsiderados casos de cotistas com certificação de conclusão do ensino médio por pontuação no Exame Nacional do Ensino Médio e titulação por meio da educação de jovens e adultos ${ }^{11}$.

Figura 1 - Distribuição dos cotistas por tipo de escola, UFRGS, 2017.

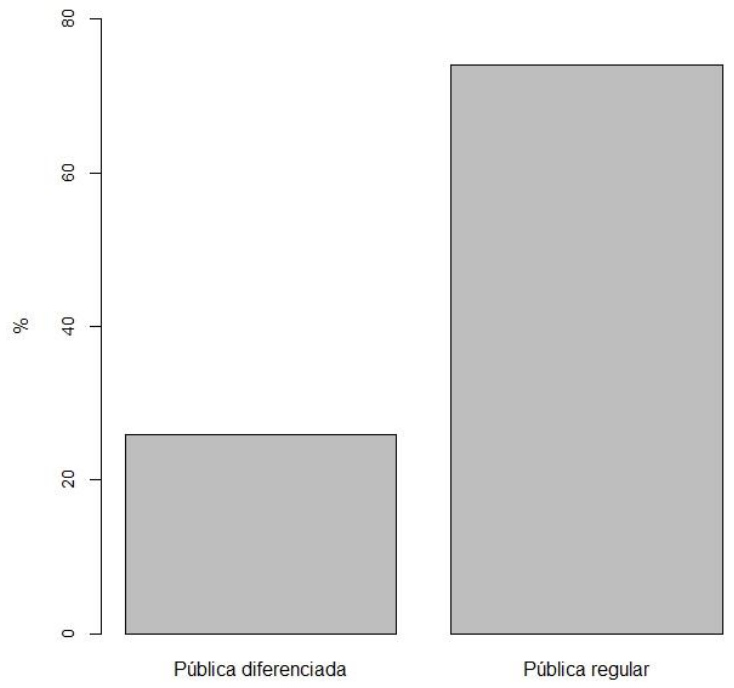

Fonte: Elaborado a partir de banco de dados da PROGRAD/UFRGS.

A partir de cruzamentos simples, apresenta-se em seguida uma série de dados e boxplots que mostram a diferença na ocupação das vagas entre cotistas oriundos de escolas públicas regulares e diferenciadas. Tal diferença, como anunciado, é maior na L3 em relação às demais modalidades de cotas (ver Figura 2) e é progressivamente maior nos cursos de maior concorrência (ver Figuras 3 e 4).

Figura 2 - Tipo de escola por tipo de cota, UFRGS, 2017.

\footnotetext{
11 As matrículas em escolas diferenciadas representavam 24,1\% das matrículas de nível médio da rede pública em Porto Alegre, RS. Esse dado tem origem nos microdados do BRASIL/INEP, 2018. 


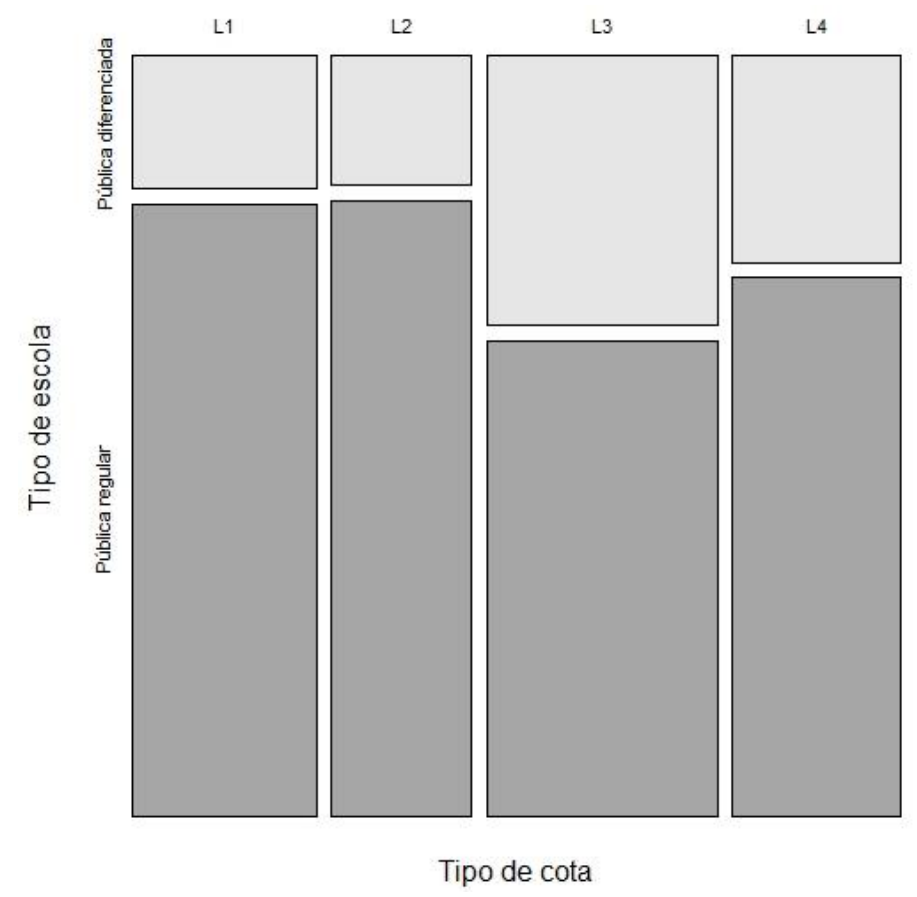

Fonte: Elaborado a partir de banco de dados da PROGRAD/UFRGS.

Tabela 4 - Tipo de escola por tipo de cota, UFRGS, 2017.

\begin{tabular}{c|r|r|r|r|r}
\hline Tipo de escola & \multicolumn{1}{c|}{ L1 } & \multicolumn{1}{l|}{ L2 } & \multicolumn{1}{c|}{ L3 } & \multicolumn{1}{c|}{ L4 } & \multicolumn{1}{c}{ Total } \\
\hline \multirow{3}{*}{ Pública diferenciada } & 109 & 80 & 275 & 154 & $\mathbf{6 1 8}$ \\
& $17.6 \%$ & $12.9 \%$ & $44.5 \%$ & $24.9 \%$ & \\
& $\underline{18.0 \%}$ & $\underline{17.4 \%}$ & $\underline{36.2 \%}$ & $\underline{27.7 \%}$ & $\underline{\mathbf{2 6 . 0} \%}$ \\
\hline \multirow{2}{*}{ Pública regular } & 498 & 380 & 484 & 401 & $\mathbf{1 7 6 3}$ \\
& $28.2 \%$ & $21.6 \%$ & $27.5 \%$ & $22.7 \%$ & \\
& $\underline{82.0 \%}$ & $\underline{82.6 \%}$ & $\underline{63.8 \%}$ & $\underline{72.3 \%}$ & $\underline{\mathbf{7 4 . 0} \%}$ \\
\hline Total & $\mathbf{6 0 7}$ & $\mathbf{4 6 0}$ & $\mathbf{7 5 9}$ & $\mathbf{5 5 5}$ & $\mathbf{2 3 8 1}$ \\
\hline
\end{tabular}

Fonte: Elaborado a partir de banco de dados da PROGRAD/UFRGS.

Nota: Proporção por linha/horizontal em itálico e proporção por coluna/vertical sublinhado.

Os dados descritos na Tabela 4 demostram que, na ocupação das vagas reservadas com base na lei de cotas, sem filtro por cursos, os estudantes oriundos das escolas diferenciadas ocuparam em maior percentual as vagas na modalidade L3 (36,2\%), pouco mais de $10 \%$ acima do valor esperado quando comparado às demais modalidades. As modalidades L1 e L2 têm percentuais de ocupação de vagas por estudantes vindos de escolas diferenciadas menores que o esperado $(18 \%$ e $17,4 \%$, respectivamente). A modalidade L4 é a que mais se aproxima da proporção de ocupação esperada ( $26 \%$ ) para estudantes desse tipo de escola. Além disso, do total de estudantes egressos de escolas diferenciadas que obtiveram vagas na UFRGS no ano de 2017, 44,5\% concentraram-se na modalidade L3. Isso significa que os beneficiários da categoria L3 que estudaram em escolas diferenciadas são em grande parte candidatos que não se enquadram em critérios de reserva de vagas étnico-raciais e de renda.

Essa distribuição favorável à ocupação de estudantes oriundos de escolas diferenciadas na modalidade L3 se intensifica quando tomamos como referência os dez cursos de maior concorrência, conforme Figura 3. 
Figura 3 - Tipo de escola por tipo de cota nos dez cursos de maior prestígio, UFRGS, 2017.

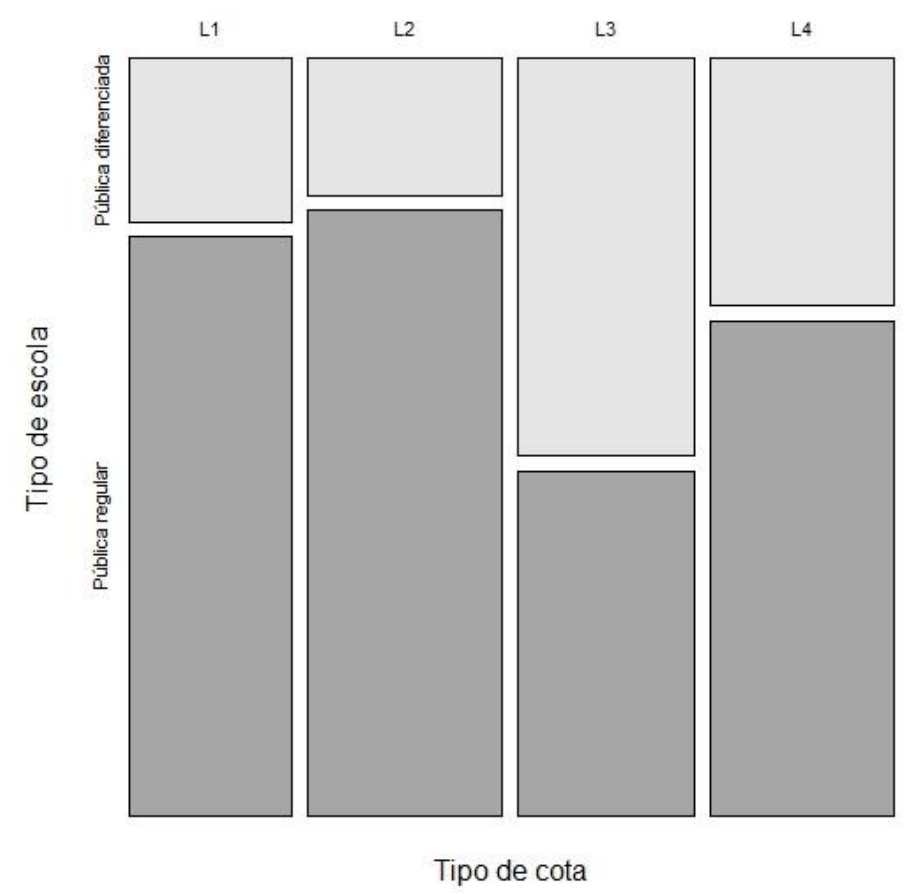

Fonte: Elaborado a partir de banco de dados da PROGRAD/UFRGS.

Tabela 5 - Tipo de escola por tipo de cota nos dez cursos de maior prestígio, UFRGS, 2017.

\begin{tabular}{r|r|r|r|r|r}
\hline Tipo de escola & \multicolumn{1}{c|}{ L1 } & \multicolumn{1}{c|}{ L2 } & \multicolumn{1}{c|}{ L3 } & \multicolumn{1}{c|}{ L4 } & \multicolumn{1}{c}{ Total } \\
\hline \multirow{3}{*}{ Pública diferenciada } & 17 & 17 & 45 & 29 & $\mathbf{1 0 8}$ \\
& $15.7 \%$ & $15.7 \%$ & $41.7 \%$ & $26.9 \%$ & \\
& $\underline{22.1 \%}$ & $\underline{18.5 \%}$ & $\underline{53.6 \%}$ & $\underline{33.3 \%}$ & $\underline{\mathbf{3 1 . 8} \%}$ \\
\hline \multirow{3}{*}{ Pública regular } & 60 & 75 & 39 & 58 & $\mathbf{2 3 2}$ \\
& $25.9 \%$ & $32.3 \%$ & $16.8 \%$ & $25.0 \%$ & \\
& $\underline{77.9 \%}$ & $\underline{81.5 \%}$ & $\underline{46.4 \%}$ & $\underline{66.7 \%}$ & $\underline{\mathbf{6 8 . 2} \%}$ \\
\hline Total & $\mathbf{7 7}$ & $\mathbf{9 2}$ & $\mathbf{8 4}$ & $\mathbf{8 7}$ & $\mathbf{3 4 0}$ \\
\hline
\end{tabular}

Fonte: Elaborado a partir de banco de dados da PROGRAD/UFRGS.

Nota: Proporção por linha/horizontal em itálico e proporção por coluna/vertical sublinhado.

Nos dez cursos de maior concorrência no CV de 2017, o efeito da origem escolar na ocupação da vaga torna-se mais evidente. A Tabela 5 mostra que $41,7 \%$ dos estudantes cotistas de escolas diferenciadas ocuparam vaga na L3. Além disso, 53,6\% das vagas da L3 foram ocupadas por alunos oriundos de escolas públicas diferenciadas. Com relação à modalidade de ingresso L4, a proporção efetiva de vagas ocupadas por estudantes de escolas diferenciadas $(33,3 \%)$ mantém-se próxima da proporção média total, ou seja, $31,8 \%$.

O curso de medicina, que se mantém tradicionalmente como aquele de maior densidade e que exige a maior nota de corte dos candidatos, amplia a tendência de favorecimento do ingresso de candidatos oriundos de escolas diferenciadas. Essa distorção pode ser visualizada na Figura 4. 
Figura 4 - Tipo de escola por tipo de cota em Medicina, UFRGS, 2017.

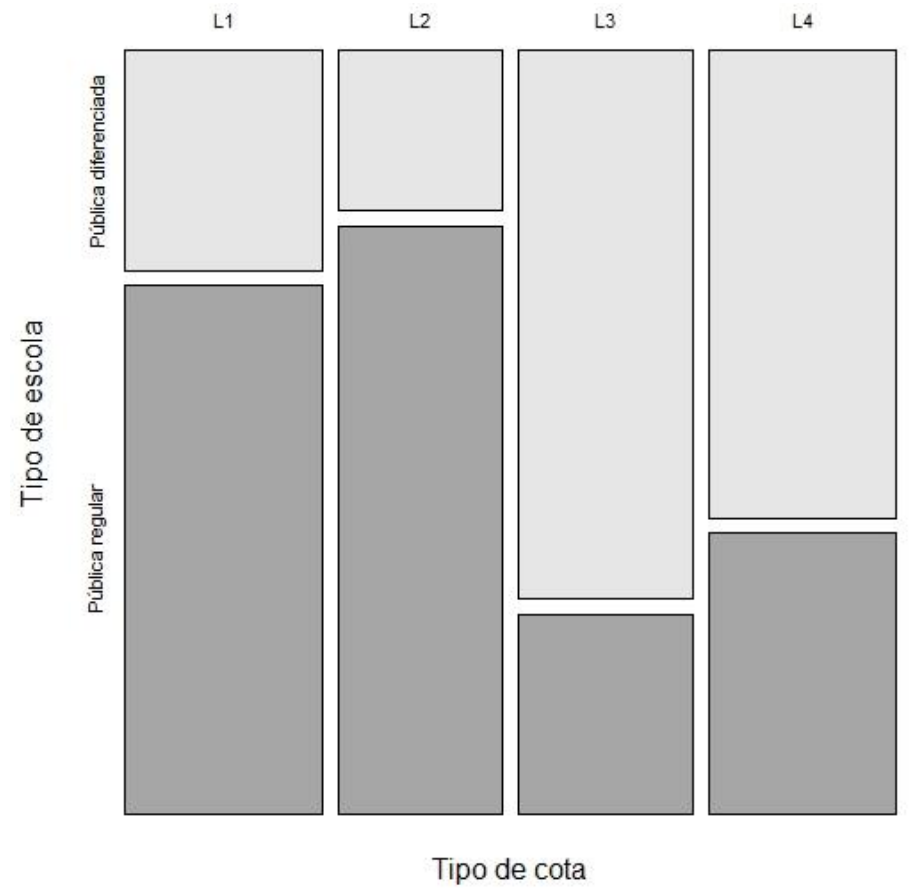

Fonte: Elaborado a partir de banco de dados da PROGRAD/UFRGS.

Tabela 6 - Tipo de escola por tipo de cota em Medicina, UFRGS, 2017.

\begin{tabular}{c|c|c|c|c|c}
\hline Tipo de escola & L1 & L2 & L3 & L4 & Total \\
\hline \multirow{3}{*}{ Pública diferenciada } & 5 & 3 & 11 & 10 & $\mathbf{2 9}$ \\
& $17.2 \%$ & $10.3 \%$ & $37.9 \%$ & $34.5 \%$ & \\
& $29.4 \%$ & $\underline{21.4 \%}$ & $\underline{73.3 \%}$ & $\underline{62.5 \%}$ & $\underline{\mathbf{4 6 . 8} \%}$ \\
\hline \multirow{3}{*}{ Pública regular } & 12 & 11 & 4 & 6 & $\mathbf{3 3}$ \\
& $36.4 \%$ & $33.3 \%$ & $12.1 \%$ & $18.2 \%$ & \\
& $\underline{70.6 \%}$ & $\underline{78.6 \%}$ & $\underline{26.7 \%}$ & $\underline{37.5 \%}$ & $\underline{\mathbf{5 3 . 2} \%}$ \\
\hline Total & $\mathbf{1 7}$ & $\mathbf{1 4}$ & $\mathbf{1 5}$ & $\mathbf{1 6}$ & $\mathbf{6 2}$ \\
\hline
\end{tabular}

Fonte: Elaborado a partir de banco de dados da PROGRAD/UFRGS.

Nota: Proporção por linha/horizontal em itálico e proporção por coluna/vertical sublinhado.

No curso de medicina, a ampliação da ocupação das vagas por estudantes de escolas diferenciadas verifica-se em todas as modalidades (L1 29,4\%; L2 21,4\%; L3 73,3\% e L4 62,5\%). A média de estudantes de escolas diferenciadas que ocupam as quatro modalidades de vagas na totalidade dos cursos da Universidade é de $26 \%$, portanto significativamente inferior aos percentuais de ocupação no curso de medicina, como se vê na Tabela 6.

$\mathrm{Na}$ modalidade L2, que reúne os critérios de baixa renda e raça/etnia, observa-se uma proporção menor na ocupação das vagas $(21,4 \%)$ em relação às demais modalidades. Na modalidade L3, que não seleciona por critérios de renda e raça, predomina largamente a ocupação de vagas por egressos de escolas diferenciadas. Por outro lado, do total de egressos de escolas diferenciadas, há uma concentração nas modalidades L3 e L4, 37,9\% e 34,5\%, respectivamente. Inversamente, entre os egressos de escolas regulares, a concentração ocorre em maior proporção nas modalidades L1 e L2, com 36,4\% e $33,3 \%$, respectivamente.

Em outros termos, embora em todos as situações analisadas haja maior concentração de estudantes egressos de escolas diferenciadas na modalidade L3, observa-se que a concentração destes tende a diminuir nesta modalidade, conforme se amplia a concorrência para ingresso no curso, distribuindo-se mais entre as modalidades. Inversamente, observa-se que a modalidade L3 passa a ter uma proporção significativamente maior de estudantes egressos de escolas diferenciadas em relação aos 
estudantes de escolas regulares. Tais dados indicam a capacidade desses alunos de aproveitamento da vaga L3 em todas as situações e de acesso nas outras modalidades quando se tem aumento da concorrência e da dificuldade de acesso devido à nota de corte alta.

Tais diferenças são bem menores nos cursos de menor concorrência (ver Figura 5), prevalecendo a maior participação de estudantes oriundos de escolas públicas regulares. Mesmo nesses cursos, L3 e L4 apresentam diferenças em relação às outras duas modalidades. Esse fato indica que há estratificação horizontal entre egressos de escolas diferenciadas e escolas regulares, uma vez que, conforme se intensifica a concorrência para ingresso nos cursos superiores, os egressos das escolas públicas regulares têm suas chances diminuídas.

Figura 5 - Tipo de escola por tipo de cota nos dez cursos de menor prestígio, UFRGS, 2017.

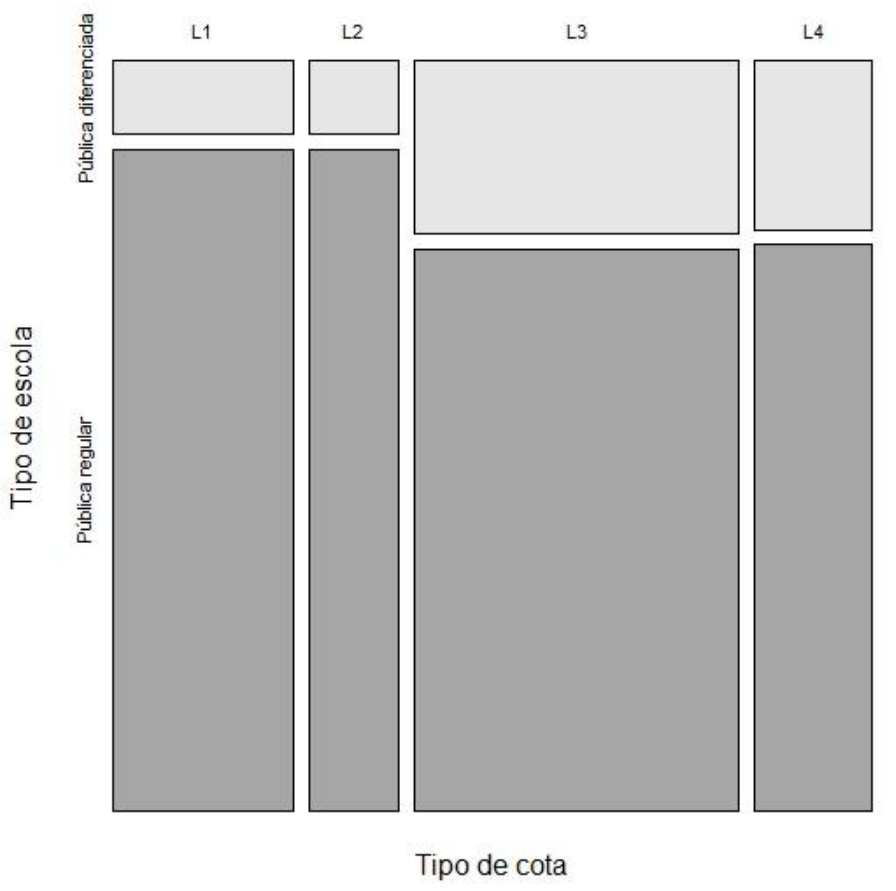

Fonte: Elaborado a partir de banco de dados da PROGRAD/UFRGS.

Tabela 7 - Tipo de escola por tipo de cota nos dez cursos de menor prestígio, UFRGS, 2017.

\begin{tabular}{r|r|r|r|r|r}
\hline Tipo de escola & \multicolumn{1}{c|}{ L1 } & \multicolumn{1}{c|}{ L2 } & \multicolumn{1}{c|}{ L3 } & \multicolumn{1}{c|}{ L4 } & Total \\
\hline \multirow{3}{*}{ Pública diferenciada } & 4 & 2 & 17 & 6 & $\mathbf{2 9}$ \\
& $13.8 \%$ & $6.9 \%$ & $58.6 \%$ & $20.7 \%$ & \\
& $\underline{10.0 \%}$ & $\underline{10.0 \%}$ & $\underline{23.6 \%}$ & $\underline{23.1 \%}$ & $\underline{\mathbf{1 8 . 4 \%}}$ \\
\hline \multirow{3}{*}{ Pública regular } & $27.9 \%$ & 18 & 55 & 20 & $\mathbf{1 2 9}$ \\
& $\underline{90.0 \%}$ & $\underline{90.0 \%}$ & $42.6 \%$ & $15.5 \%$ & \\
\hline Total & $\mathbf{4 0}$ & $\mathbf{2 0}$ & $\mathbf{7 6 . 4 \%}$ & $\underline{\mathbf{7 6 . 9} \%}$ & $\underline{\mathbf{8 1 . 6} \%}$ \\
\hline $\mathbf{2 6}$ & & $\mathbf{1 5 8}$ \\
\hline
\end{tabular}

Fonte: Elaborado a partir de banco de dados da PROGRAD/UFRGS

Nota: Proporção por linha/horizontal em itálico e proporção por coluna/vertical sublinhado.

A Tabela 7 fortalece a interpretação de que os cursos menos concorridos tendem a ter suas vagas menos disputadas por estudantes egressos de escolas públicas diferenciadas. Esses cursos têm suas vagas significativamente ocupadas por estudantes egressos de escolas regulares, sobretudo nas modalidades L1 e L2, atingindo um patamar de 90\%.

Para verificar numericamente tais diferenças na ocupação das vagas, utilizou-se o coeficiente de contingência. É importante reconhecer que o coeficiente de contingência é uma técnica não inferencial, sem verificação de causalidade, utilizado para análises iniciais com varáveis discretas. Trata- 
se de uma descrição numérica da força de uma relação percebida entre valores esperados e notados (AGRESTI; FINLAY, 2012).

A Tabela 8 apresenta uma relação de coeficientes entre o tipo de escola e modalidades de cota, de forma dicotômica, entre todos os cursos da UFRGS, entre os dez primeiros cursos no quesito dificuldade de acesso e concorrência e no curso de medicina. Esse conjunto de coeficientes de contingência indica que a força de diferença de ocupação da vaga entre alunos oriundos das escolas regulares em relação aos das escolas diferenciadas é, em média, maior na medicina (média 0.23) que nos demais cursos; em média, maior nos dez cursos mais concorridos (média 0.14) em relação aos demais cursos da UFRGS (média 0.09); e que a força de diferença de ocupação da vaga entre alunos oriundos das escolas diferenciadas em relação aos das escolas regulares é maior na L3, em especial, em medicina.

Tabela 8 - Relação dos coeficientes de contingência de Pearson entre tipo de escola por modalidade de cota, filtrado por nível de curso, UFRGS, 2017.

\begin{tabular}{c|l|c|c|c|c}
\hline \multirow{2}{*}{ Tipo de escola } & \multirow{2}{*}{ Cursos (filtro) } & \multicolumn{4}{|c}{ Modalidade de cota } \\
\cline { 3 - 6 } & & L1/Outras & L2/Outras & L3/Outras & L4/Outras \\
\hline \multirow{2}{*}{ Diferenciada/Regular } & Todos & 0.11 & 0.10 & 0.16 & 0.02 \\
& 10 primeiros cursos & 0.11 & 0.17 & 0.26 & 0.02 \\
\cline { 3 - 5 } & Medicina & 0.21 & 0.26 & 0.29 & 0.18 \\
\hline
\end{tabular}

Fonte: Elaborado a partir de banco de dados da PROGRAD/UFRGS.

Nota: Entre variáveis dicotômicas - Regular/Diferenciada e Modalidade de cota/Outras modalidades.

Os dados da Tabela 8 corroboram os cruzamentos anteriormente apresentados. Esse conjunto de dados demonstra que alunos de escolas públicas diferenciadas e regulares ocuparam de forma desigual as vagas destinadas às ações afirmativas na UFRGS em 2017, e tal diferença se acirra nos cursos de maior concorrência.

Apesar de os valores dos coeficientes apresentarem pouca força estatística, apontam uma assimetria importante no acesso ao direito à educação. Essa desigualdade é especialmente relevante quando se considera o ideal compensatório das políticas afirmativas na educação superior brasileira. Essa análise, se reproduzida com dados nacionais e com maior precisão na construção da variável de origem escolar, pode evidenciar diferenças ainda maiores na ocupação das vagas públicas de educação superior.

A partir da perspectiva da teoria da desigualdade efetivamente mantida, com sua abordagem sobre as desigualdades horizontais, compreende-se que a realidade escolar, em sua heterogeneidade marcada mesmo dentro da rede pública, preserva possibilidades diferenciais no acesso à educação superior. Quando se considera que o acesso a escolas públicas diferenciadas, bem como acessos escolares anteriores e posteriores, estão em geral relacionados a vantagens familiares em termos de capitais socioeconômicos e culturais, percebe-se que essas vantagens reverberam no acesso à educação superior. Esse fenômeno ocorre mesmo por dentro das tentativas de compensação da desigualdade social organizadas pela política federal de ações afirmativas no ingresso à educação superior.

A análise apresentada converge com aquela realizada por André Salata (2018), a partir de dados longitudinais, em que se argumenta que apenas a expansão do ensino superior no Brasil não garantiria a democratização no acesso. Sua análise confirma que as políticas públicas desenhadas para a democratização do acesso e a redução das desigualdades econômicas - políticas afirmativas - são decisivas para a redução na desigualdade de acesso ao ensino superior nas décadas recentes. Apesar disso, cabe ressaltar a importância da análise das desigualdades horizontais no interior desse nível de ensino, em que as universidades públicas federais figuram como locais de preferência e distinção para aqueles com mais condições de acesso. 


\section{CONSIDERAÇÕES FINAIS}

Os resultados da análise aqui desenvolvida evidenciam que a origem escolar é um elemento importante na definição do acesso à universidade pública, no contexto da diminuição da desigualdade vertical, já que se mantém certa desvantagem horizontal na ocupação de vagas entre as quatro modalidades de cotas analisadas.

A política de cotas, atualmente sistematizada na Lei 12.711, favorece, em apenas uma de suas modalidades, o acesso de estudantes oriundos da rede pública de nível médio de modo indistinto, desconsiderando a estratificação existente na rede brasileira de ensino público. Os dados apresentados neste artigo indicam que tal modalidade da política de cotas encontra limites na correção da distorção no acesso à educação superior pública federal.

É possível lidar com a hipótese de que os resultados aqui encontrados sejam verificados também em escala nacional, dada a presença de características semelhantes que informam o acesso à educação superior. Primeiro, apesar de haver particularidades entre as escolas públicas nas diferentes unidades da federação, há uma estrutura da estratificação escolar similar no conjunto do País. Segundo, a política de cotas tem um arranjo único para o acesso à educação superior pública federal, reproduzindo os mesmos critérios para a ocupação das vagas nas diferentes modalidades. Terceiro, as universidades públicas federais têm maior concorrência pelas suas vagas devido ao fato de oferecerem educação gratuita e de alta qualidade.

O processo de disputa para ingresso na educação superior pública no País envolve competitividade não apenas no nível dos candidatos, mas também das instituições das quais são egressos. Nesse caso, o quase-mercado já teorizado no âmbito da concorrência pelas escolas parece se refletir no acesso ao próximo nível de ensino. Este aspecto, no âmbito das políticas de ações afirmativas, também se impõe, uma vez que a competitividade pelas vagas reservadas não foi superada com a introdução da política de cotas por desconsiderar a heterogeneidade interna das escolas públicas. Esse fenômeno indica a existência de um quase-mercado escolar público para o acesso à educação superior, gerado por uma competitividade no interior das redes públicas de ensino médio.

Dessa forma, as políticas de ações afirmativas são indispensáveis para a redução da desigualdade no acesso à educação superior, embora se verifique a necessidade de aprimoramentos a fim de beneficiar mais amplamente os estudantes com menor chance na disputa competitiva pelas vagas restritas que existem na universidade pública. Um dos pontos sustentados por este artigo é que a política de cotas não considerou a heterogeneidade do ensino médio público. Assim como em outros países, e como em outros níveis de ensino, o ensino médio brasileiro público também é diverso e desigual. Há diversos caminhos de escolarização possíveis na rede pública, e nem todos eles agrupam estudantes e famílias que estão em situação de desvantagens. A cota L3, no caso da UFRGS, utiliza apenas o critério da escola pública. Ao ser aplicado sem combinação com outros quesitos, privilegia o acesso de estudantes de contextos escolares anteriores diferenciados e diminui as chances dos candidatos desfavorecidos por sua origem social, que mais necessitam das ações afirmativas.

Nesse sentido, a política de cotas acaba por negligenciar a complexidade da estratificação educacional no nível médio, reforçando, nessa modalidade específica das cotas para escolas públicas, o acesso privilegiado de grupos cujas vantagens socioeconômicas já os inserem em escolas públicas diferenciadas, de acesso restrito e distintivo.

É importante salientar os avanços significativos que a política de cotas produziu ao garantir o acesso à educação superior por parte de segmentos historicamente excluídos. A ocupação da reserva de vagas das ações afirmativas na universidade pública deve considerar que segmentos mais vulneráveis em termos socioeducacionais (pessoas pretas, pardas e indígenas de baixa renda) não têm ocupado a totalidade das vagas destinadas a eles. Além disso, parte dessas vagas podem estar sendo ocupadas por candidatos não condizentes com os critérios de renda e raça, tendo em vista as dificuldades de caracterização do perfil. Por um lado, a análise da renda familiar seria um dado objetivo; entretanto, sua comprovação é complexa. Além do mais, a partir do ano em análise (2017), houve novos desenvolvimentos quanto à aplicação de critérios étnico-raciais, com a instalação de comissões de heteroidentificação na UFRGS. Em que pesem tais limites, este artigo indica que o critério escola pública 
(L3) pode ser insuficiente para corrigir as distorções das desigualdades no acesso à educação superior quando não associado a critérios de renda e étnico-raciais que caracterizam segmentos sociais historicamente desfavorecidos.

Como um todo, as políticas de ações afirmativas ou políticas de cotas para as instituições federais de ensino superior cumprem uma função de alto valor na redução das desigualdades de acesso ao ensino superior público no Brasil, constituindo-se como uma possibilidade de ingresso de populações historicamente marginalizadas desse espaço. A análise realizada neste artigo explorou especificidades do acesso ao conjunto das vagas reservadas para atender à política de ações afirmativas. Verificou-se que grupos específicos de estudantes egressos da rede pública de nível médio possuem condições socioeconômicas e experiência escolar diferenciadas. Os dados aqui analisados corroboram com a bibliografia sobre o tema, mostrando que desigualdades escolares tendem a se manter de forma complexa e horizontalizada.

\section{REFERÊNCIAS}

AGRESTI, Alan; FINLAY, Barbara. Métodos estatísticos para as ciências sociais. 4. ed. Porto Alegre: Penso, 2012.

ANHAIA, Bruna Cruz de. A "lei de cotas" no ensino superior brasileiro: reflexões sobre a política pública e as Universidades Federais. Tese (Doutorado em Sociologia) - Programa de Pós-Graduação em Sociologia, Universidade Federal do Rio Grande do Sul. Porto Alegre, 2019. Disponível em: http://hdl.handle.net/10183/196058. Acesso em: 28 ago. 2019.

ARRETCHE, Marta (org.). Trajetórias das desigualdades: como o Brasil mudou nos últimos 50 anos. São Paulo: Unesp, 2015.

BELLO, Luciane. Política de ações afirmativas na UFRGS: o processo de resiliência na trajetória de vida de estudantes cotistas negros com bom desempenho acadêmico. Dissertação (Mestrado) - Faculdade de Educação, Universidade Federal do Rio Grande do Sul, Porto Alegre, 2011. Disponível em: https://lume.ufrgs.br/handle/10183/35089. Acesso em: 28 ago. 2019.

BOUDON, Raymond. Efeitos perversos e ordem social. Rio de Janeiro: Zahar, 1979.

BOUDON, Raymond. A desigualdade das oportunidades: a mobilidade social nas sociedades industriais. Brasília: UNB, 1981.

BOURDIEU, Pierre; PASSERON, Jean-Claude. A reprodução: elementos para uma teoria do sistema de ensino. 5. ed. Petrópolis, RJ: Vozes, 2012.

BRASIL. Instituto Nacional de Estudos e Pesquisas Educacionais Anísio Teixeira. Plano Nacional de Educaşão PNE 2014-2024. Lei Federal 13.005, de 25 de junho de 2014. Brasília, DF: Inep, 2014.

BRASIL. Instituto Nacional de Estudos e Pesquisas Educacionais Anísio Teixeira. Censo da Educação Básica: Sinopse Estatística da Educação Básica 2018. Disponível em: http://www.inep.gov.br/superior/censosuperior/sinopse/default.asp. Acesso em: 10 out. 2019.

BRASIL. Lei n 12.711, de 29 de agosto de 2012. Dispõe sobre o ingresso nas universidades federais e nas instituições federais de ensino técnico de nível médio e dá outras providências. Diário Oficial da União, Brasília, 30 ago. 2012. Seção 1, p. 1. 
Brasil. Lei 13.409, de 28 de dezembro de 2016. Altera a Lei no 12.711, de 29 de agosto de 2012, para dispor sobre a reserva de vagas para pessoas com deficiência nos cursos técnico de nível médio e superior das instituições federais de ensino. Diário Oficial da União, Brasília, 29 dez. 2016, p. 3.

CAREGNATO, Célia. Elizabete.; OLIVEN, Arabela Campos. Educação superior e políticas de ação afirmativa no Rio Grande do Sul: desigualdades e equidade. Educar em Revista, Curitiba, Brasil, n. 64, p. 171-187, abr./jun. 2017. DOI: 10.1590/0104-4060.47764.

COLEMAN, James (org.). Equality of educational opportunity. Washington: U.S. Government Printing Office, 1966.

COSTA, Márcio da; KOSLINSKI, Mariane Campelo. Quase-mercado oculto: disputa por escolas "comuns" no Rio de Janeiro. Cadernos de Pesquisa, v. 41, n. 142, p. 245-266. 2011.

COSTA, Márcio. Prestígio e hierarquia escolar: estudo de caso sobre diferenças entre escolas em uma rede municipal. Revista Brasileira de Educação, v. 13, n. 39, p. 455-469. 2008.

COSTA, Márcio; CAMARGO, Paulo de. Lógica de quase-mercado. Revista Educação, n. 153. 2010. Disponível em: http://revistaeducacao.uol.com.br/formacao-docente/153/artigo234697-1.asp. Acesso em: 18 jun. 2015.

COSTA, Márcio; KOSLINSKI, Mariane. Escolha, estratégia e competição por escolas públicas. ProPosições, v. 23, n. 2, p. 195-213. 2012.

FERES JÚNIOR, João. Ação afirmativa: política pública e opinião. Revista Sinais Sociais, Rio de Janeiro v. 3, n. 8, p. 38-77. 2008.

FERES JÚNIOR, João. Aspectos normativos e legais das políticas de ação afirmativa. In: FERES JÚNIOR, João.; ZONINSEIN, Jonas. (ed.). Ação afirmativa e universidade: experiências nacionais comparadas. Brasília: UnB, 2005. p. 43-66.

GRISA, Gregório. As ações afirmativas na UFRGS: uma análise do processo de implantação. Dissertação (Mestrado em Educação) - Faculdade de Educação, Universidade Federal do Rio Grande do Sul, Porto Alegre, 2010. Disponível em: https://lume.ufrgs.br/handle/10183/24818. Acesso em: 20 jun. 2019.

GRISA, Gregório. Ações afirmativas na UFRGS: racismo, excelência acadêmica e cultura do reconhecimento. Tese (Doutorado em Educação) - Faculdade de Educação, Universidade Federal do Rio Grande do Sul, Porto Alegre, 2015. Disponível em: https://lume.ufrgs.br/handle/10183/115959. Acesso em: 19 jul. 2019.

HAECHT, Anne Van. Sociologia da Educação: a escola posta à prova. Porto Alegre: Artmed, 2008.

JOSÉ, Adriano Rodrigues. Processo de institucionalização do Programa de Ações Afirmativas na Universidade Federal do Rio Grande do Sul: embates, disputas e contradições. Dissertação (Mestrado em Educação) Faculdade de Educação, Universidade Federal do Rio Grande do Sul, Porto Alegre, 2017. Disponível em: https://lume.ufrgs.br/handle/10183/157592. Acesso em: 25 maio 2019.

LÓPEZ, Laura Cecília. "Que América Latina se sincere”: uma análise antropológica das políticas e poéticas do ativismo negro em face às ações afirmativas e às reparações no Cone Sul. Tese (Doutorado em Antropologia social) - Programa de Pós-Graduação em Antropologia social, Universidade Federal do Rio Grande do Sul, Porto Alegre, 2009. Disponível em: http://www.lume.ufrgs.br/handle/10183/16871. Acesso em: 28 ago. 2019. 
LUCAS, Samuel R. Effectively Maintained Inequality: education transitions, track mobility, and social background effects. American Journal of Sociology, v. 106, n. 6, p. 1642-1690. 2001.

LUCAS, Samuel R. Stratification theory, socioeconomic background, and educational attainment: a formal analysis. Rationality and Society, v. 21, n. 4, p. 459-511. 2009.

MAGALHÃES, Marcos Nascimento; LIMA, Antonio Carlos Pedroso. Noções de probabilidade e estatística. 7. ed. São Paulo: EDUSP, 2013.

MASSON, Philippe. A produção de Os Herdeiros. Revista Pós Ciências Sociais, v. 13, n. 25, p. 105-136. 2016.

MOEHLECKE, Sabrina. Ações Afirmativas: história e debates no Brasil. Cadernos de Pesquisa, n. 117, p. 197-217. 2002.

NOGUEIRA, Cláudio M. M.; NONATO, Bréscia F.; RIBEIRO, Gustavo M.; FLONTINO, Sandra R. D. Promessas e limites: o Sisu e sua implementação na Universidade Federal de Minas Gerais. Educação em Revista, v. 33. 2017.

NOGUEIRA, Fernanda. Cotas raciais no curso de Medicina da UFRGS na perspectiva docente: rupturas e configurações tecidas na garantia do direito à educação superior pública. Dissertação (Mestrado em Educação) - Programa de Pós-Graduação em Educação. Pontifícia Universidade Católica do Rio Grande do Sul. Porto Alegre, 2015. Disponível em: http://meriva.pucrs.br/dspace/bitstream/10923/7125/1/000466689-Texto\%2BCompleto-0.pdf. Acesso em: 10 jul. 2019.

NOGUEIRA, Maria Alice. Relação família-escola: novo objeto na sociologia da educação. Paidéia. 1998, vol.8, n.14-15, p. 91-103.

OLIVEN, Arabela Campos 2009. Ações afirmativas na Universidade Federal do Rio Grande do Sul e o seu significado simbólico. Educação (UFSM). 34, n. 1, jan./abr. 2009.

PROLO, Felipe. Possibilidades e oportunidades de atuação politica: estudo sobre a formação do grupo de trabalho de ações afirmativas no processo de reivindicação por cotas no ingresso da UFRGS.

Dissertação (Mestrado em Sociologia) - Programa de Pós-Graduação em Sociologia, Universidade Federal do Rio Grande do Sul, Porto Alegre, 2011. Disponível em:

http://hdl.handle.net/10183/39523. Acesso em: 27 jun. 2019.

ROSISTOLATO, Rodrigo. Choice and access to the best schools of Rio de Janeiro: a rite of passage. Vibrant, v. 12, n. 2, p. 380-416. 2015.

SALATA, André Ricardo. Ensino Superior no Brasil das últimas décadas. Redução nas desigualdades de acesso?. Tempo Social, v. 30, n. 2, p. 219-253. 2018.

SOUZA, Eliane Almeida de. Dez anos de cotas na UFRGS: um estudo das ações afirmativas na perspectiva do acesso, permanência e empoderamento dos alunos negros diplomados. Tese (Doutorado em Educação) - Faculdade de Educação, Universidade Federal do Rio Grande do Sul, Porto Alegre, 2017. Disponível em: https://lume.ufrgs.br/handle/10183/169243. Acesso em: 10 jul. 2019. 
UFRGS. Comissão Permanente de Seleção. Vestibular da UFRGS 2017: provas comentadas - processo de avaliação. Porto Alegre: Editora da UFRGS, 2017.

Submetido: $04 / 12 / 2019$

Aprovado: 02/08/2020 